\title{
MĂSURI DE PROTECŢIE INTEGRATĂ ASUPRA MALADIILOR FOLIARE LA CEREALELE DE TOAMNĂ
}

\section{Bivol Alexei ${ }^{1,2}$, Bădărău Sergiu'1 , Rusu Ștefan², Sasanelli Nicola³, Bivol Elisaveta ${ }^{1}$, lurcu-Străistaru Elena ${ }^{2}$}

\author{
${ }^{1}$ Universitatea Agrară de Stat din Moldova, or. Chișinău \\ 2Institutul de Zoologie al MECC, or. Chișinău, Republica Moldova \\ 3/nstitutul de Protecție a Plantelor (IPP), secția Nematologie, sectorul Bari, Italia \\ E-mail: iurcuelena@mail.ru
}

https://doi.org/10.53937/9789975315975.30

\begin{abstract}
This work presents the results of investigations in the frame state testing the products for phytosanitary use Lab 05-F, SC, Lab 06-F, SE, Duo SCC, Virtuoz EC, Mirage 45 EC as fungicides on autumn cereals crops during the period of vegetation of 2017-2018 years. It was established the ethyological component, grade of intensity and the frequency of the phytopathogenic agents in the period of vegetation at autumn wheat and barley as they are: Erysiphe graminis f. sp. tritici, s.p. hordei, Puccinia anomala, Puccinia recondita, Helminthosporium gramineum, Helminthosporium tritici-repentiss Helminthosporium teres, Septoria graminum, Septoria nodorum anomala, Fusarium graminearum. On the base of the experimental results obtained the preparations tested had a high biological effiency in the combat of leaf diseases at autumn cereals in critical phases of the periods of vegetation. have been included in the integrate protection system.
\end{abstract}

Key words: automn cereals, plant disease, biological efficiency, fungicides, frequency and intensity, pathogeni agents, measuser of integrate protection.

\section{INTRODUCERE}

Explorarea agroecosistemelor antropizate de cereale de toamnă include diverse obiective cu valori incontestabile, pentru asigurarea productivităţii înalte și de calitate a producției de cerealiere, în diverse sisteme de producții agricole și zone ecologice de specializare din Republica Moldova. Anual, se semnalează, în aspectul parametrilor ecologobiologici, diverse daune și pierderi de producţii biologice și agricole facili- 
tate de inluența condiţiillor favorabile, pentru dezvoltarea complexelor de organisme nocive, ca agenţi fitoparazitari. Creșterea producţiei de cereale este posibilă prin aplicarea tehnologiilor moderne, care presupun cultivarea unor soiuri și hibrizi cu potenţial major și cu rezistenţă înaltă asupra organismelor nocive, ajustarea unor sisteme de protecţie integrată a plantelor, capabile să asigure recolta de cariopse calitativă și cantitativă. Complexul procedeelor de protecţie a cerealelor de toamnă prevede utilizarea tuturor verigilor agrotehnologice, cum sunt: respectarea asolamentului, utilizarea seminţelor sănătoase, respectarea epocii optime de semănat, profunzimi de încorporare în sol a seminţelor și densităţi optime a plantelor, aplicarea raţională a fertilizanţ̧ilor, lucrări de întreţinere agrotehnică, tratamente fitosanitare speciale conform pragului economic de dăunare. $[1,2,4,6]$.

Culturile cerealiere de toamnă, în special grâul și orzul sunt supuse de la germinare până la recoltare, în deosebi în perioada de vegetaţie unor presiuni din partea diferitor agenţi patogeni, provocatori de boli specifice radiculare, foliare, paiului, inflorescenţei și ale spicului, care prezintă un pericol deosebit pentru calitatea și cantitatea recoltei, și care pot determina, în condiţii favorabile epidemii masive prin compromiterea producţiei de cariopse. Monitoringul fitosanitar și diagnosticul acestor boli realizat pe baza aspectelor simptomatologice este esenţial în vederea adoptării rapide a măsurilor de prevenire și protecţie a pagubelor conform situaţiei acute de contaminare și provocare acută $[3,4,5]$.

În ansamblu, ca urmare a atacului diferitor boli, în special a aparatului foliar din faza înfrăţirii până la formarea spicului, se produce uscarea prematură a frunzelor, cu modificări morfo-fiziologice prin reducerea procesului de fotosinteză, intensităţii respiraţiei și transpiraţiei, creștere retardată, spaţiu foliar redus, talia scurtă a paiului, boabele șiștave, mărunte fapt ce determină o producţie de cariopse redusă și necalitative. Anual, pierderile de recoltă pot ajunge până la 40\%, iar variaţiile fiind determinate de influenţa factorilor de mediu, fon agrotehnic nerespec- 
tat, material semincier necondiţionat și nerespectarea tehnologiilor corespunzătoare.

Aparatul foliar al plantelor cerealiere este afectat de un complex de agenţi patogeni, care include câteva zeci de specii de diversă natură etiologică, patologică și patografică diferită, însă drept agenți patogeni care provoacă diverse maladii cheie de importanţă agrobiologică pot fi estimaţi și cei de origine micotică cum sunt: Erysiphe graminis f. sp. tritici, s.p. hordei, Puccinia anomala, Puccinia recondita, Helminthosporium gramineum, Helminthosporium tritici-repentiss Helminthosporium teres, Septoria graminum, Septoria nodorum anomala, Pyrenophora graminea, Pyrenophora teres, Fusarium graminearum etc.

În agrocenozele cerealiere de toamnă eficienţa prevenirii pagubelor provocate de boli se realizează prin aplicarea unui sistem complex de combatere integrată, care presupune utilizarea tuturor posibilităţilor de prevenire a atacului agenţilor patogeni, ce combină monitoringul fitosanitar cu stabilirea pragului economic de daună, iar acest indice determină utilizarea procedeelor de prevenire sau combatere a gradului de atac în plantaţiile remarcate $[4,5,6]$.

\section{MATERIALE ȘI METODE}

Investigaţiile efectuate în scop de stabilire a stării fitosanitare în aspect fitopatologic cu depistarea maladiilor specifice, componenţei etiologice, semnelor patografice au fost realizate pe diverse sectoare cu cerealiere de toamnă a Zonei de Centru a Republicii Moldova. S-a determinat eficiența biologică a produselor micotice Lab 05-F, SC, Lab 06-F, SE, Duo SCC, Virtuoz EC, Mirage 45 EC, în diverse variante și doze indicate în programul de cercetare-testare. Experienţele au fost amplasate și realizate în Cooperativa Agricolă de Producţie "Răzagro-Prim", comuna Răzeni, raionul laloveni, în perioda de vegetaţie a anului 2018, cu efectuarea evidenţelor fitosanitare prin sondaje de rută și staţionare, în constatarea bolilor supuse tratamentelor chimice. 
Montarea experienţei s-a efectuat prin metoda dreptunghiului latin. Fiecare variantă includea câte patru repetiţii. Dimensiunile parcelelor pentru fiecare repetiţie au constituit $25 \times 2 \mathrm{~m}$. Pe sectorul experimental au fost efectuate câte două tratamente chimice la grâu și orz în faza formării paiului și spicului cerealier (18.04. 09; 22.05. 09). Observările fenologice și evidenţele s-au efectuat periodic conform cerinţelor "Îndrumări metodice pentru testarea produselor chimice și biologice de protecţie a plantelor de dăunători, boli și buruieni în R. Moldova" [7].

Observările fenologice și sondajele de evidenţă s-au efectuat periodic conform „Îndrumări metodice pentru testarea produselor chimice și biologice de protecţie a plantelor de dăunători, boli și buruieni în Republica Moldova" [2, 7] și „Îndrumări metodice la executarea lucrărilor de încercare de stat a produselor chimice și biologice de protecţie și stimulare a creșterii plantelor agricole și silvice în Republica Moldova" [7, 8].

\section{REZULTATE ȘI DISCUŢII}

Reieșind din actualităţile și motivaţiile estimate mai sus, scopul investigaţiilor constau în depistarea bolilor foliare cheie la culturile cerealiere de grâu și orz din Zona de Centru și aplicarea unui complex de măsuri de protecţie chimică cu noi fungicide, inofensive pentru mediu, și eficiente pentru agenţii fitopatogeni foliari. Combaterea bolilor foliare a paiului și spicului în perioada de vegetaţie, constituie o verigă tehnologică eficientă și foarte importantă pentru protecţia plantelor conform pronosticului și avertizărilor individuale pe fiecare boală depistată. Utilizarea corectă a fungicidelor în doza omologată, cu respectarea tuturor măsurilor de securitate, asigură o eficacitate înaltă în combaterea complexă a unor boli foliare și ale spicului.

Succesul combaterii chimice a bolilor în cadrul tehnologiilor intensive de cultivare a grâului și orzului de toamnă, determină utilizarea corectă a termenelor de efectuare a tratamentelor, cu aplicarea noilor fungicide cu înaltă eficacitate și lărgirea sortimentului de preparate chimice omologate. În acest context testarea eficienţei biologice a unor noi produse de uz fitosanitar cu acţiune fungicidă asupra bolilor principale foliare la cerealele de toamnă constituie obiectivele de bază ale cercetărilor efectuate în 
perioada de toamnă a anilor 2017-2018.

Reeșind din cele menţionate mai sus s-au trasat următoarele obiective:

1. Studierea dinamicii dezvoltării făinării, ruginilor, septoriozei, fuzariozei și helmintosporiozei la grâu și orz prin sondaje de evidenţă cu determinarea în baza lor a frecvenţei și intensităţii gradului de atac;

2. Analiza comparativă a parametrilor fitosanitari în stabilirea componenţei etiologice și patografice a agenţilor patogeni: Erysiphe graminis $f$. sp. hordei, Puccinia anomala, Pyrenophora graminea, Helminthosporium tritici-repentiss Helminthosporium teres, Septoria graminum, Septoria nodorum anomala, Pyrenophora teres, Septoria graminum, Septoria nodorum, Fusarium graminearum în aspectul semănătorilor productive și variantelor experimentale realizate.

3. Determinarea eficienţei biologice a fungicidelor Lab 05-F, SC, Lab 06-F, SE, Duo SCC, Virtuoz EC, Mirage 45 EC asupra ciupercilor Erysiphe graminis f. sp. hordei, Puccinia anomala, Pyrenophora graminea, Pyrenophora teres.

Temperaturile moderate $\left(15-20^{\circ} \mathrm{C}\right)$, umiditatea relativă e aerului, ploile sporabice, ceaţa, roua, semănăturile dense, cu aerisire slabă, administrarea unor doze mari de azot soiurilor sensibile, au fost factorii care au favorizat apariţia și evoluţia epidemică a agenţilor patogeni de ordin micotic cum sunt: Erysiphe graminis D.C., Puccinia recondita (Rob.) Desm., Puccinia anomala Rostr., Septoria tritici Rob. et Desm., Septoria graminum Desm., Helminthosporium gramineum Rabenhz. et Schecht. și Helminthosporium teres Sacc. atât la grâul cât și la orzul de toamnă (4, 3, 2). Pentru obţinerea unor producţii ridicate în condiţii climatice favorabile de dezvoltare a bolilor foliare la nivelul pragului economic de daună este obligatorie folosirea fungicidelor, chiar dacă sunt respectate toate metodele alternative de protecţie a plantelor $(7,8)$. În această situaţie se impune aplicarea unor tratamente chimice care să asigure stoparea evoluţiei patogenilor și declanșarea intensivă a bolilor la plante în perioade critice de dezvoltare. După condiţiile de umiditate și temperatură, teritoriul Cooperativei Agricole de Producţie "Răzagro-Prim", comuna Răzeni, raionul laloveni face parte din raionul II agroclimateric al Republicii Moldova și se caracterizează cu o sumă de $3200-3300^{\circ} \mathrm{C}$, coeficientul hidrotermic con- 
stituind 0,7-0,9. Temperatura medie lunară pozitivă a aerului se menţine în decurs de 9 luni (03-11). Îngheţuri târzii, după datele multianuale, se înregistrează până în a doua decadă a lunii mai. Temperaturile medii diurne mai înalte de $10^{\circ} \mathrm{C}$ se semnalează în circa 180 de zile. Suma precipitaţiilor alcătuiește 340-435 mm, dintre care $70 \mathrm{~mm}$ revin lunii iunie. Din datele multianuale putem face concluzia că teritoriul Cooperativei Agricole de Producţie "Răzagro-Prim", comuna Răzeni, raionul laloveni este favorabil atât pentru cultivarea cerealelor, cât și pentru dezvoltarea în masă a Erysiphe graminis $f$. sp. tritici, Puccinia recondita, Fusarium graminearums, Septoria tritici, Septoria nodorum etc. Condiţile climaterice în toamna anului 2017 și în perioada de vegetaţie a anului 2018 sunt prezentate în tabelul 1.

Toamna anului $2017 \mathrm{~s}$-a caracterizat prin temperatura medie a aerului $\left(11,7^{\circ} \mathrm{C}\right)$ și depuneri atmosferice $(125,3 \mathrm{~mm})$ în limitele mediilor multianuale care au fost favorabile pentru dezvoltarea agenților patogeni la culturile cerialiere în perioada de vegetație.

Tabelul 1. Condițiile meteorologice în Zona de Centru a Republicii Moldova, aa. 2017-2018

\begin{tabular}{|c|c|c|c|c|c|c|c|c|c|}
\hline \multirow{3}{*}{\multicolumn{2}{|c|}{$\begin{array}{l}\text { Luna, anul, } \\
\text { decada }\end{array}$}} & \multicolumn{4}{|c|}{ Temperatura aerului, ${ }^{\circ} \mathrm{C}$} & \multirow{2}{*}{\multicolumn{2}{|c|}{$\begin{array}{l}\text { Suma lunară a preci- } \\
\text { pitaţiilor atmosferi- } \\
\mathrm{ce}, \mathrm{mm}\end{array}$}} & \multirow{2}{*}{\multicolumn{2}{|c|}{$\begin{array}{l}\text { Umiditatea relativă } \\
\text { a aerului, \% }\end{array}$}} \\
\hline & & \multicolumn{2}{|c|}{$2017-2018$} & \multicolumn{2}{|c|}{$\begin{array}{l}\text { Temperatura medie } \\
\text { lunară, }{ }^{\circ} \mathrm{C}\end{array}$} & & & & \\
\hline & & Max & $\min$ & $\begin{array}{l}2017- \\
2018\end{array}$ & $\begin{array}{l}\text { Media mul- } \\
\text { tianuală }\end{array}$ & $\begin{array}{l}2017- \\
2018\end{array}$ & $\begin{array}{l}\text { Media mul- } \\
\text { tianuală }\end{array}$ & $\begin{array}{l}2017- \\
2018\end{array}$ & $\begin{array}{l}\text { Media mul- } \\
\text { tianuală }\end{array}$ \\
\hline \multirow{3}{*}{$\begin{array}{l}09 \\
17\end{array}$} & 1 & 31,0 & 11,9 & 20,1 & & 0,9 & & 57 & \\
\hline & 2 & 30,7 & 12,6 & 21,5 & & 4,0 & & 54 & \\
\hline & 3 & 24,3 & 5,6 & 14,0 & & 11,0 & & 64 & \\
\hline \multicolumn{2}{|c|}{$\begin{array}{l}\text { Media mul- } \\
\text { tianuală }\end{array}$} & 30,7 & 5,6 & 18,5 & 16,1 & 15,9 & 35,0 & 58 & 67 \\
\hline \multirow{3}{*}{$\begin{array}{l}10 \\
17\end{array}$} & 1 & 19,4 & 4,0 & 10,6 & & 53,0 & & 64 & \\
\hline & 2 & 24,2 & 6,2 & 14,4 & & 0,9 & & 66 & \\
\hline & 3 & 15,8 & $-0,1$ & 7,6 & & 21,0 & & 75 & \\
\hline \multicolumn{2}{|c|}{$\begin{array}{l}\text { Media mul- } \\
\text { tianuală }\end{array}$} & 24,2 & $-0,1$ & 10,9 & 10,2 & 74,9 & 32,0 & 68 & 74 \\
\hline
\end{tabular}




\begin{tabular}{|c|c|c|c|c|c|c|c|c|c|}
\hline \multirow{3}{*}{$\begin{array}{l}11 \\
17\end{array}$} & 1 & 15,1 & 2,1 & 7,2 & & 3,5 & & 78 & \\
\hline & 2 & 16,2 & 1,3 & 5,8 & & 2,0 & & 80 & \\
\hline & 3 & 10,1 & $-2,2$ & 3,7 & & 29,0 & & 85 & \\
\hline \multicolumn{2}{|c|}{$\begin{array}{l}\text { Media anu- } \\
\text { ală }\end{array}$} & 16,2 & $-2,2$ & 5,6 & 4,1 & 34,5 & 41,0 & 81 & 70 \\
\hline \multirow{3}{*}{$\begin{array}{l}12 \\
17\end{array}$} & 1 & 10,9 & $-2,8$ & 3,5 & & 47,0 & & 85 & - \\
\hline & 2 & 12,8 & $-3,6$ & 2,7 & & 14,0 & & 81 & - \\
\hline & 3 & 11,7 & $-6,0$ & 3,8 & & 12,0 & & 81 & - \\
\hline \multicolumn{2}{|c|}{$\begin{array}{l}\text { Media mul- } \\
\text { tianuală }\end{array}$} & 12,8 & $-6,0$ & 3,3 & $-0,1$ & 73,0 & 33,0 & 82 & 85 \\
\hline \multirow{3}{*}{$\begin{array}{l}01 \\
18\end{array}$} & 1 & $+10,6$ & $-2,4$ & 3,5 & - & 7,2 & - & 86 & - \\
\hline & 2 & $+3,4$ & $-10,2$ & $-2,6$ & - & 25,0 & - & 83 & - \\
\hline & 3 & $\begin{array}{r}+7,7 \\
\end{array}$ & $-10,6$ & $-3,1$ & - & 0,0 & - & 78 & - \\
\hline \multicolumn{2}{|c|}{$\begin{array}{l}\text { Media mul- } \\
\text { tianuală }\end{array}$} & $+10,6$ & $-10,6$ & $-2,2$ & $-3,4$ & 32,2 & 23,0 & 82 & 85 \\
\hline \multirow{3}{*}{$\begin{array}{l}02 \\
18\end{array}$} & 1 & 9,0 & $-2,2$ & 1,7 & - & 24,0 & - & 82 & - \\
\hline & 2 & 2,2 & $-5,4$ & $-0,4$ & - & 23,0 & - & 88 & - \\
\hline & 3 & $+0,3$ & $-14,2$ & $-6,4$ & - & 8,8 & - & 77 & - \\
\hline \multicolumn{2}{|c|}{$\begin{array}{l}\text { Media mul- } \\
\text { tianuală }\end{array}$} & 9,0 & $\mid-14,2$ & $-1,7$ & $-2,7$ & 55,8 & 30,0 & 82 & 82 \\
\hline \multirow{3}{*}{$\begin{array}{l}03 \\
18\end{array}$} & 1 & 10,8 & $-13,3$ & $-2,1$ & - & 12,0 & - & 79 & - \\
\hline & 2 & 13,6 & $-9,6$ & $+2,6$ & - & 68,0 & - & 87 & - \\
\hline & 3 & 19,0 & $-5,4$ & $+1,9$ & - & 24,0 & - & 72 & - \\
\hline \multicolumn{2}{|c|}{$\begin{array}{l}\text { Media mul- } \\
\text { tianuală }\end{array}$} & 19,0 & $-13,3$ & $+0,8$ & 2,6 & 104,0 & & 79 & 76 \\
\hline \multirow{3}{*}{$\begin{array}{l}04 \\
18\end{array}$} & 1 & 23,5 & 2,1 & 12,3 & & 0,4 & & 53 & \\
\hline & 2 & 24,1 & 7,0 & 15,5 & & 0,0 & & 51 & \\
\hline & 3 & 27,4 & 6,4 & 17,5 & & 2,9 & & 48 & \\
\hline \multicolumn{2}{|c|}{$\begin{array}{l}\text { Media mul- } \\
\text { tianuală }\end{array}$} & 27,4 & 2,1 & 15,1 & 10,4 & 3,3 & 35,0 & 51 & 65 \\
\hline \multirow{3}{*}{$\begin{array}{l}05 \\
18\end{array}$} & 1 & 30,4 & 10,8 & 20,7 & - & 0,9 & - & 48 & - \\
\hline & 2 & 24,0 & 9,3 & 16,0 & - & 14,0 & - & 60 & - \\
\hline & 3 & 28,2 & 14,1 & 21,3 & - & 3,0 & - & 41 & - \\
\hline \multicolumn{2}{|c|}{$\begin{array}{l}\text { Media mul- } \\
\text { tianuală }\end{array}$} & 30,4 & 9,3 & 19,3 & 16,1 & 17,9 & 50,0 & 50 & 71 \\
\hline \multirow{3}{*}{$\begin{array}{l}06 \\
18\end{array}$} & 1 & 29,7 & 13,2 & 21,8 & 19,7 & 0,0 & 75,0 & 48 & 64 \\
\hline & 2 & & & & - & & - & & - \\
\hline & 3 & & & & - & & - & & - \\
\hline
\end{tabular}


În general considerăm că, în Zona de Centru a Republicii Moldova, condiţiile climatice în perioada octombrie - decembrie, cu precipitații atmosferice în sumă de 182,4 mm au fost favorabile pentru dezvoltarea culturilor de grâu de toamnă. În același timp, condiţiile au fost favorabile și pentru infecţia primară și dezvoltarea bolilor micotice, cum ar fi făinarea și rugina brună etc.

Din literatura știinţifică de specialitate se cunoaște că temperaturile de $16-19^{\circ} \mathrm{C}$, umiditatea relativă e aerului cât mai ridicată, ploile, ceaţa, roua, semănăturile prea dese, cu aerisire slabă, administrarea unor doze mari de azot și soiurile sensibile, sunt factori care favorizează apariţia și evoluţia epidemiilor de rugină brună, făinare, helmintosporioză etc.

În funcţie de faza fenologică se fac 1-2 tratamente:

1) pentru combaterea bolilor foliare, momentul optim pentru tratament este sfârșitul înfrăţirii - împăierea. Dacă sunt condiţii favorabile (precipitaţii, temperaturi ridicate) pentru apariţia mai devreme a bolilor și dacă acestea se manifestă acut, tratamentul poate fi aplicat și la mijlocul înfrăţirii;

2) pentru protejarea spicului și a ultimei frunze se face un tratament la înspicare.

Tratamentele au drept scop protejarea frunzelor noi, în special când se anunţă vreme umedă. În general, momentele critice care trebuie luate în consideraţie pentru culturile orz de toamnă fără boli sunt următoarele: a) de la sfârșitul înfrăţirii până la apariţia primului internod, pentru bolile de colet și tulpină; b) de la burduf la înspicare - înflorire, pentru protecţia frunzei stindard, la presiuni mari de infecţie. Eficienţa biologică a folosirii fungicidului Lab 05-F, SC împotriva bolilor grâului de toamnă s-a calculat după formula:

E. b. $\%=\frac{\text { I. } m .- \text { I. e. }}{\text { I. } m .} \times 100$, unde:

E. b. - eficienţa biologică;

I. m. - intensitatea dezvoltării bolii în varinta martor;

I. e. - intensitatea dezvoltării bolii în variantele experimentale. 
Prelucrarea statistică a datelor s-a efectuat după Dospehov, 1979.

În zona Centru a Republicii Moldova, condiţiile cilmaterice în perioada de vegetaţie a anului 2017-2018 au fost relativ favorabile pentru realizarea înfecţiei primare și dezvoltarea în masă a bolilor cheie în culturile cerealelor de toamnă. Datele experimentale privind testarea eficienţei biologice a preparatelor Lab 05-F, SC, Lab 06-F, SE, Duo SCC, Virtuoz $E C$, Mirage $45 E C$ în calitate de noi fungicide la cerealele de toamnă se prezintă în tabelul 2. Condiţiile cilmaterice în perioada de vegetaţie a anului 2018 au fost puțin favorabile pentru realizarea înfecţiei primare și dezvoltarea ruginii brune, făinării, septoriozei, fuzaririozei și altor boli ale grâului și orzului de toamnă în zona de Centru a Republicii Moldova.

Datele experimentale privind testarea eficienţei biologice a preparatului Lab 05-F, SC în calitate de fungicid împotriva ciupercilor Erysiphe graminis D.C., Puccinia recondita (Rob.) Desm., Puccinia anomala Rostr., Septoria tritici Rob. et Desm., Septoria graminum Desm., Helminthosporium gramineum Rabenhz. et Schecht., și Helminthosporium teres Sacc se prezintă în tabelul 2.

Tabelul 2. Eficienţa biologică a fungicidului Lab 05-F, SC şi Duo SCC în combaterea ruginelor la grâu şi orz de toamnă Cooperativa Agricolă de Producţie "Răzagro-Prim" anul 2018

\begin{tabular}{|l|l|l|l|l|l|}
\hline $\begin{array}{l}\text { Nr. } \\
\text { d/o }\end{array}$ & Variantele experienţelor & $\begin{array}{l}\text { Doza la } \\
\text { ha }\end{array}$ & $\begin{array}{l}\text { Frecvenţa } \\
\text { atacului, \% }\end{array}$ & $\begin{array}{l}\text { Intensitatea atacu- } \\
\text { lui, \% }\end{array}$ & $\begin{array}{l}\text { Eficienţa biologi- } \\
\text { că, \% }\end{array}$ \\
\hline 1. & Martor fără tratamente & - & 33,0 & 24,3 & 0,0 \\
\hline 2. & Duo SCC, $-0,25$ I/ha & 0,75 & 3,1 & 1,2 & 91,6 \\
\hline 3. & Lab 05-F, SC - 0,5 I/ha & 0,5 & 4,1 & 1,8 & 87,4 \\
\hline 4. & Lab 05-F, SC - 0,75 I/ha & 0,75 & 3,8 & 1,1 & 92,3 \\
\hline & DL $\mathbf{0 , 9 5}$ & & & $\mathbf{3 , 2 3}$ \\
\hline
\end{tabular}

Astfel, în varianta martor fără tratamente chimice, frecvenţa atacului de a constituit în ultima evidenţă 25,7\%, la o intensitate a dezvoltării bolii de 14,3\%.

În variantele experimentale frecvența atacului de complexul de rugini foliare a constituit 33\% în varianta standard (Martor netratat), în varianta 
Lab 05-F, SC - 0,5 I/ha și 3,8\%, varianta Lab 05-F, SC - 0,75 I/ha, 3,8\% Duo SCC, $-0,25 \mathrm{l} / \mathrm{ha}, 3,1 \%$.

Intensitatea dezvoltării bolilor a constituit 1,8\% în varianta Lab 05-F, SC - 0,5 I/ha și 1,1\% în varianta Lab $05-F$, SC- 0,75 I/ha, faţă de 1,2\% în Duo SCC - 0,75 I/ha).

Eficienţa biologică a utilizării fungicidului Lab $05-\mathrm{F}$, SC împotriva bolilor foliare constituit 87,4\% în varianta Lab 05 -F, SC - 0,5 I/ha și 92,3\% în varianta Lab 05-F, SC - 0,75 I/ha, faţă de 91,6\% în varianta, Duo SCC, $-0,25 \mathrm{I} / \mathrm{ha}, 91,6 \%$.

Datele prelucrării statistice a rezultatelor obţinute arată că eficienţa biologică a produsului Lab 05-F, SC în calitate de fungicid împotriva ciupercilor fitopatogene a fost la nivelul de 92,3\% la preparatul Lab 05-F, SC - 0,5 I/ha.

În tabelul 3 sunt prezentate rezultatele determinării eficienţei biologice a tratamentelor cu Lab $05-F$, SC și Mirage 45 EC în combaterea făinării provocată de ciupercă Erysiphe graminis f. sp. tritici la grâu și orz de toamnă, cu eficienţe biologice de la $82,2 \%-86,9 \%$.

Tabelul 3. Eficienţa biologică a fungicidelor Lab 05-F, SC şi Mirage 45 EC în combaterea făinării grâului. Cooperativa Agricolă de Producţie "Răzagro-Prim" anul 2018

\begin{tabular}{|l|l|l|l|l|l|}
\hline $\begin{array}{l}\text { Nr. } \\
\text { d/o }\end{array}$ & Variantele experienţei & Doza la ha & $\begin{array}{l}\text { Frecvenţa } \\
\text { atacului, \% }\end{array}$ & $\begin{array}{l}\text { Intensitatea ata- } \\
\text { cului, \% }\end{array}$ & $\begin{array}{l}\text { Eficienţa biolo- } \\
\text { gică, \% }\end{array}$ \\
\hline 1. & Martor fără tratamente & - & 32,3 & 20,7 & 0,0 \\
\hline 2. & Mirage 45 EC & 1,0 & 4,6 & 1,5 & 86,0 \\
\hline 3. & Lab 05-F, SC - 0,5 I/ha & 0,5 & 5,2 & 1,9 & 82,2 \\
\hline 4. & Lab 05-F, SC - 0,75 I/ha & 0,75 & 4,3 & 1,4 & 86,9 \\
\hline & DL $\mathbf{0 , 9 5}$ & \multicolumn{5}{|l}{$\mathbf{9 4}$} \\
\hline
\end{tabular}

Condițiile cilmaterice în perioada de vegetaţie a anului 2018 au fost puțin favorabile pentru realizarea înfecţiei primare și dezvoltarea în masă a sfâșierii frunzelor de orz, pătării reticulate a frunzelor de orz și altor boli ale orzului de toamnă în Zona de Centru a Republicii Moldova.

Datele experimentale privind testarea eficienţei biologice a preparatului Mirage 45 EC și Virtuoz EC în calitate de fungicid împotriva ciupercii Puccinia anomala, Helminthosporium tritici-repentis, Septoria tritici, Septoria nodorum se prezintă în tab. 4.

Astfel, în varianta martor fără tratamente chimice, frecvenţa atacului 
de rugină pitică a constituit în ultima evidenţă 28,5\%, la o intensitate a dezvoltării bolii de 19,7\%.

Tabelul 4. Eficienţa biologică a fungicidului Mirage 45 EC şi Virtuoz EC în combaterea complexelor de boli foliare la cultura de orz, anul 2018

\begin{tabular}{|c|c|c|c|c|c|}
\hline $\begin{array}{l}\mathrm{Nr} . \\
\mathrm{d} / \mathrm{o}\end{array}$ & Variantele experienţelor & $\begin{array}{l}\text { Doza la } \\
\text { ha }\end{array}$ & $\begin{array}{l}\text { Frecvenţa } \\
\text { atacului, \% }\end{array}$ & $\begin{array}{l}\text { Intensitatea atacului, } \\
\%\end{array}$ & $\begin{array}{l}\text { Eficienţa biologi- } \\
\text { că, \% }\end{array}$ \\
\hline 1. & Martor fără tratamente & - & 28,5 & 19,7 & 0,0 \\
\hline 2. & Virtuoz EC & 0,5 & 3,4 & 1,2 & 87,6 \\
\hline 3. & Mirage $45 \mathrm{EC}$ & 0,8 & 4,1 & 1,7 & 82,3 \\
\hline \multirow[t]{2}{*}{4.} & Mirage $45 \mathrm{EC}$ & 1,0 & 3,0 & 1,1 & 88,7 \\
\hline & DL 0,95 & & & & 3,02 \\
\hline
\end{tabular}

În variantele experimentale frecvența atacului de boli foliare a constituit după tratament 3,4\% în varianta Virtuoz EC - 0,5 I/ha), 3,4\% în varianta Mirage 45 EC - 0,8 - I/ha, 4,1\% și 3,0\% în varianta Mirage 45 EC - 1,0 I/ha.

Intensitatea dezvoltării bolilor foliare la orz a constiuit după tratament 1,7\% în varianta Mirage 45 EC - 0,8 I/ha și 1,1\% în varianta Mirage 45 EC $1,0 \mathrm{l} / \mathrm{ha}$, faţă de Virtuoz EC 1,2\%, 0,5 I/ha.

Eficienţa biologică a utilizării fungicidului Mirage 45 EC împotriva complexului de boli foliare a constituit 82,3\% în varianta Mirage $45 \mathrm{EC}-0,8 \mathrm{l} / \mathrm{ha}$ și 88,7\% în varianta Mirage 45 EC - 1,0 I/ha, faţă de 87,6\% în varianta Virtuoz EC - 0,5 I/ha, fapt ce denotă eficienţa biologică înaltă în combaterea bolilor remarcate comparativ cu martorul netratat, unde frecvenţa și intensitatea atacului a variat în valori de 19,7 - 28,5\%, indici foarte înalţi de afecţiune.

\section{CONCLUZII}

1. Condiţiile cilmaterice în perioada de vegetaţie a anilor 2017-2018 au fost medii favorabili în extinderea și frecvenţa realizării înfecţiei primare și secundare de dezvoltare în masă a maladiilor foliare la cultura de grâu și orz, atingând valori medii de 28,5\%-33,0\% maladiile foliare la culurile cerealiere formele de rugini, făinări, sfâșieri și pătări reticulate a frunzelor septoriozei, fuzariozei și helmintosporiozei.

2. S-a efectuat analiza comparativă a parametrilor fitosanitari în stabilirea componenţei etiologice și patografice a agenţilor patogeni foliari la cultura de grâu și orz cum sunt: Erysiphe graminis f. sp. hordei, Puccinia anomala, Pyrenophora graminea, Helminthospo- 
rium tritici-repentiss Helminthosporium teres, Septoria graminum, Septoria nodorum anomala, Pyrenophora teres, Septoria graminum, Septoria nodorum, Fusarium graminearu în aspectul semănătorilor productive și variantelor experienţelor realizate.

3. S-a determinat eficienţa biologică, la culurile cerealiere de toamnă, a tratamentului cu noi preparate fungicide Lab 05-F, SC, Lab 06-F, $S E$, Duo SCC, Virtuoz EC, Mirage 45 EC în combaterea agenţilor patogeni micotici, care atinge valori înalt eficiente de $82,2 \%$ - 92,3\%;

4. În baza rezultatelor experimentale realizate și analizate preparatele fungicide noi testate Lab 05-F, SC, Lab 06-F, SE, Duo SCC, Virtuoz $E C$, Mirage 45 EC au fost recomandate pentru a fi incluse în sistemul de protecţie a cerealelor de toamnă asupra complexelor de boli foliare.

Investigațiile au fost realizate în cadrul proiectului 15.817.02.12 F, finanțat de Consiliul Suprem pentru Știință și Dezvoltare Tehnologică al Academiei de Științe a Moldovei.

\section{BIBLIOGRAFIE}

1. Baicu T. Fitopatologie agricolă. București, Ceres, 1996, 315 p.

2. Bădărău S. Fitopatologie (generală și agricolă). Chișinău, Centr. Edit. al UASM, 2012, 595p.

3. Bădărău S., Bivol A. Fitopatologie agricolă. Chișinău, Centr. Edit. al UASM, 2007, 460 p.

4. Bădărău S., Bivol A., Nicolaescu O. Fitopatologia Agricolă UASM, 2013, 325 p.

5. Bădărău S., Gaibu Z. Bolile plantelor în Republica Moldova. Partea I. Micoze. Chișinău, Centr. Edit. al UASM, 2014, 365 p.

6. Roșca I. et al. Combaterea integrată a bolilor, buruienilor și dăunătorilor culturilor agricole. București: Editura didactică și pedagogică, 2000, 301 p.

7. Îndrumări metodice pentru testarea produselor chimice și biologice de protecţie a plantelor în Republica Moldova. Chișinău: F.E.P. Tipo-Centrală, 2002, $290 \mathrm{p}$.

8. Registrul de Stat al produselor de uz fitosanitar și al fertilizanţilor. Chișinău, 2016, 424 p. 